\title{
DECLINING MOUNTAIN SNOWPACK IN WESTERN NORTH AMERICA*
}

\author{
by Philip W. Mote, Alan F. Hamlet, Martyn P. Clark, and Dennis P. Lettenmaier
}

The West's snow resources are already declining as the climate warms.

M ountain snowpack in western North America is a key component of the hydrologic cycle, storing water from the winter (when most precipitation falls) and releasing it in spring and early summer, when economic, environmental, and recreational demands for water throughout the West are frequently greatest. In most river basins of the West, especially in Washington, Oregon, and California, snow (rather than man-made reservoirs) is the largest component of water storage; hence, the West is (to varying degrees) vulnerable to climatic variations and changes that influence spring snowpack.

AFFILIATIONS: Mote—Climate Impacts Group, Center for Science in the Earth System, University of Washington, Seattle, Washington; HAMLET-Department of Civil and Environmental Engineering, and Climate Impacts Group, Center for Science in the Earth System, University of Washington, Seattle, Washington; CLARK - Center for Science and Technology Policy Research, University of Colorado/ CIRES, Boulder, Colorado; LeTTENMAIER-Department of Civil and Environmental Engineering, and Climate Impacts Group, Center for Science in the Earth System, Seattle, Washington

*Joint Institute for the Study of the Atmosphere and the Ocean Contribution Number 1073

CORRESPONDING AUTHOR: Philip W. Mote, Climate Impacts Group, Center for Science in the Earth System, Box 354235,

University of Washington, Seattle, WA 98195

E-mail: philip@atmos.washington.edu

DOI: 10.II75/BAMS-86-I-39

In final form 3 August 2004

(C)2005 American Meteorological Society
Winter and spring temperatures have increased in western North America during the twentieth century (e.g., Folland et al. 2001), and there is ample evidence that this widespread warming has produced changes in hydrology and plants. Phenological studies indicate that in much of the West, lilacs and honeysuckles are responding to the warming trend by blooming and leafing out earlier (Cayan et al. 2001). The timing of spring snowmelt-driven streamflow has shifted earlier in the year (Cayan et al. 2001; Regonda et al. 2004; Stewart et al. 2005), as is expected in a warming climate (Hamlet and Lettenmaier 1999a). Snow extent (Robinson 1999) and depth (Groisman et al. 1994, 2003; Scott and Kaiser 2004) have generally decreased in the West, but these observations reflect valleys and plains, where snow resources melt much earlier than in the mountains and hence play a much smaller role in hydrology, especially in late spring and summer. Observations of winter and spring snowpack are frequently used to predict summer streamflow in the West but had not been used in published studies of longer-term trends until Mote (2003a) analyzed snow data for the Pacific Northwest and showed substantial declines in 1 April snowpack at most locations. Relative losses depended on elevation in a manner consistent with warming-driven trends, and statistical regression on climate data also suggested an important role of temperature both in year-to-year fluctuations and in longer-term trends at most locations. Similar results have been found in the Swiss Alps (Laternser and Schneebeli 2003; Scherrer et al. 2004). 
The present paper extends the earlier study in many important ways. First, we expand the spatial extent of analysis to incorporate the entire West from the Continental Divide to the Pacific, and from central British Columbia, Canada, south to southern Arizona and New Mexico. Second, we augment the longterm monthly manual observations of snow with a more recent (measurements dating back typically $\sim 20$ yr) dataset of daily telemetered snow observations. Finally, and most significantly, we corroborate the analysis of snow data using a hydrological model driven with observed daily temperature and precipitation data. Trends in observed snow data may reflect climatic trends or site changes (e.g., growth of the forest canopy around a snow course) over time; using the model, we attempt to distinguish the causes of observed trends.

Documenting the extent to which observed warming has influenced the West's snow resources takes on growing importance in the context of assessing the present and future impacts of global climate change. Here we describe the observed variability and trends in snowpack, relate them to climatic variables, compare with the model simulation, and point out which areas of the mountain West are most sensitive to further warming.

DATA AND MODEL. Snow course data. Spring snowpack is an important predictor of summer streamflow, and toward this end, snowpack measurements began at a few carefully chosen sites (snow courses) early in the twentieth century. Widespread by the late 1940s, these manual measurements of the water content of snowpack [or snow water equivalent (SWE)] are conducted at roughly monthly intervals. In the last 20 or so years, automated (SNOTEL) observations, which are reported at least daily, have supplemented or replaced many manual observations. An optimal date for analysis is 1 April because it is the most frequent observation date, it is widely used for streamflow forecasting, and most sites reach their peak SWE near this date [see also Serreze et al. (1999) for SNOTEL data].

Snow course data through 2002 were obtained from the National Resources Conservation Service (NRCS) Water and Climate Center (www.wcc.nrcs.usda.gov/ snow/snowhist.html) for most states in the United States; from the California Department of Water Resources for California (cdec.water.ca.gov); and from the Ministry of Sustainable Resource Management for British Columbia (http://wlapwww.gov.bc.ca/rfc/ archive/). Each state or province had different priorities in measuring SWE, with different measurement frequencies (e.g., Arizona sites were almost always visited semimonthly, while most others were visited monthly), spatial distribution (in many states the sites are well distributed, whereas sites in Washington are clustered), and longevity.

A total of 1144 data records exist from the three data sources for the region west of the Continental Divide and south of $54^{\circ} \mathrm{N}$. Of these, 824 snow records have 1 April records spanning the time period 195097 and are used in most of the analysis. For the temporal analysis, a larger subset of the 1144 snow courses was used.

Climate data. Two types of climate data are used: one to emphasize temporal variability since 1920 and one to emphasize spatial detail of mean temperature. For temporal variability, as in Mote (2003a), the 1 April SWE measurements are compared statistically with observations at nearby climate stations for the months November through March, which roughly correspond to the snow accumulation season. These climate observations are drawn from the U.S. Historical Climate Network (USHCN) (Karl et al. 1990) and from the Historical Canadian Climate Database (HCCD) (Vincent and Gullett 1999). Climate data from the nearest five stations are combined into reference time series. There is a total of 394 stations with good precipitation data and 443 with good temperature data.

Winter (December-January-February) mean site temperature for each snow course location was determined from the nearest grid point in the $4-\mathrm{km}$ interpolated Parameter-elevation Regressions on Independent Slopes Model (PRISM) dataset (Daly et al. 1994). The rms difference in elevation between the snow courses and the corresponding PRISM grid points is only $71 \mathrm{~m}$, and the mean difference is only $1 \mathrm{~m}$; errors in elevation therefore produce only very small errors in estimated site temperature.

VIC hydrologic model. The Variable Infiltration Capacity (VIC) is a physically based hydrologic model (Liang et al. 1994; Hamlet and Lettenmaier 1999a) that accounts for fluxes of water and energy at the land surface and includes three soil layers and detailed representations of vegetation to simulate movement of soil moisture upward through plants and downward through the soil by infiltration and baseflow processes. Model performance at the snow course locations is generally quite good (correlations generally $>0.6$, average 0.74 ). Performance appears to vary chiefly with the quality of interpolated station records for precipitation and temperature, which (although corrected for 
topography) are not always an accurate representation of actual conditions at each snow course location since most meteorological stations are at lower elevations.

VIC has been used in numerous climate studies of rain-dominant, transient-snow, and snowdominant basins around the world and has been well validated with observations, particularly in the mountain West, where it has been used for streamflow forecasting applications (Hamlet and Lettenmaier 1999b; Hamlet et al. 2002) and for producing climate change scenarios (Hamlet and Lettenmaier 1999a; Wood et al. 2002; Snover et al. 2003; Christensen et al. 2004). Daily values of maximum temperature $\left(T_{\max }\right)$, minimum temperature $\left(T_{\min }\right)$, and precipitation are the only variables needed; for this study, a new meteorological dataset has been developed (Hamlet et al. 2005) for 1915-97 at the VIC resolution of $0.125^{\circ} \times 0.125^{\circ}$ (approximately $12 \mathrm{~km}$ latitude $\times 10 \mathrm{~km}$ longitude). These data include an adjustment to the long-term trends from regridded USHCN and HCCD data. Calculating snowfall and snow accumulation in this way ensures consistency with observations over several decades. The VIC simulation is performed over the domain shaded gray in Fig. 1, a total of 16,526 grid points.

At 12 of the VIC grid points, snow accumulates from year to year: the model grows glaciers. These grid points correspond to locations of actual glaciers (high in the Canadian Rockies, the North Cascades, the Olympics, and Mount Rainier), but because there is no mechanism in the model for glaciers to flow downhill, the glaciers cannot achieve a realistic balance between accumulation and loss. These 12 grid points were omitted from the analysis.

SPATIAL PATTERNS OF TRENDS. At each model grid point and for each snow course location, linear trends in 1 April SWE have been calculated for 1950-97. Similar analyses have been performed for other observation dates ( 1 and 15 February through June) and other periods of record (beginning 1920,
$1930, \ldots$ 1960), but in the interest of space we focus on 1 April 1950-97 (Fig. 1). For the model, trends are not shown at low elevations, where snow is rare (mean 1 April SWE $<5 \mathrm{~cm}$ ). Largely, usually negative, relative trends are observed at such grid points but are not hydrologically relevant.

For locations where observations are available, negative trends are the rule, and the largest relative losses (many in excess of $50 \%$, some in excess of $75 \%$ ) occurred in western Washington, western Oregon, and northern California. (Relative trends less than $-100 \%$ can occur when the best-fit line passes through zero sometime before 1997; i.e., when events of nonzero SWE became increasingly rare.) Increases in SWE, some in excess of $30 \%$, occurred in the southern Sierra Nevadas of California, in New Mexico, and in some other locations in the Southwest. Decreases in the northern Rockies were mostly in the range of $15 \%-30 \%$.

Results produced by the hydrologic model compare well with the observations, and the fraction of negative trends is almost identical (75\% for observations, $73 \%$ for VIC). Many of the details are similar in VIC and in observations: for example, the mix of increases and decreases on the Arizona-New Mexico border, the increases in central and southern Nevada and decreases in eastern Nevada, and the increases in southwest Colorado. Some of the areas in Idaho and 
British Columbia showing positive trends in VIC are sampled only sparsely by observations.

Trends over the entire simulation (not shown) are broadly similar to those for the better-observed 195097 period (Fig. 1b), with the exception of the highelevation areas in British Columbia, where trends predominantly follow precipitation trends. Parts of the northern Rockies, Oregon Cascades, and northern California had positive trends during 1916-97 and negative trends during 1950-97, but most of Colorado had negative trends during 1916-97 and positive trends during 1950-97. As will be discussed below, and by Hamlet et al. (2005, manuscript submitted to J. Climate, hereafter HMCL), these differences are primarily explained by different spatial patterns of precipitation trends in each period.

The VIC simulation also reveals an interesting and significant characteristic of these reductions that is evident in both time periods: in most mountain

\section{a. Cascades}



c. California

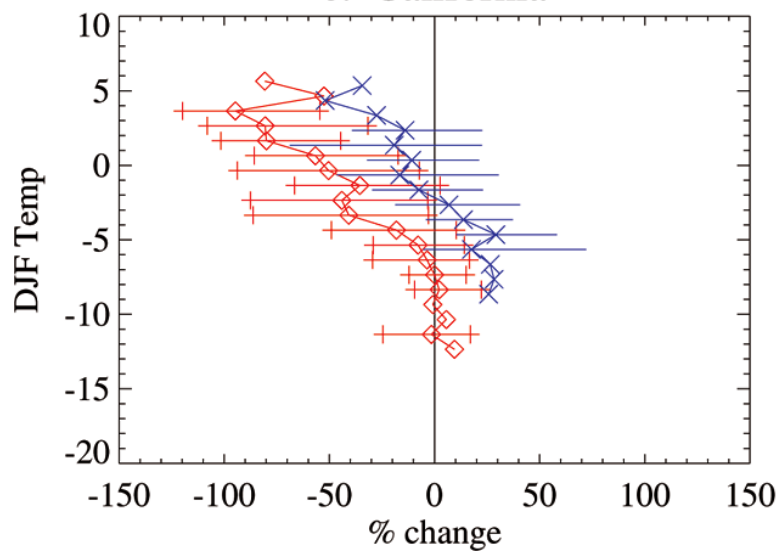

ranges, the largest relative losses occur in areas at lower elevation with warmer midwinter temperatures. At the resolution of this VIC simulation, several large river valleys in British Columbia and Montana are identifiable because they show SWE decreasing more than on the surrounding higher ground. In the Sierra Nevadas, losses at moderate elevations (including the northern Sierra, where the mean snow course elevation is $1900 \mathrm{~m}$ and the maximum is $2600 \mathrm{~m}$ ) give way to gains at high elevation (mainly in the southern Sierra, where the mean snow course elevation is $2600 \mathrm{~m}$ and the maximum is $3500 \mathrm{~m}$ ).

The dependence on elevation, or more generally on mean winter temperature, is clearer when the trends are binned by mean winter temperature (Fig. 2). In the Cascades and the mountains of California, there is a clear dependence of mean trend (and range of trends) on temperature, with the warmest
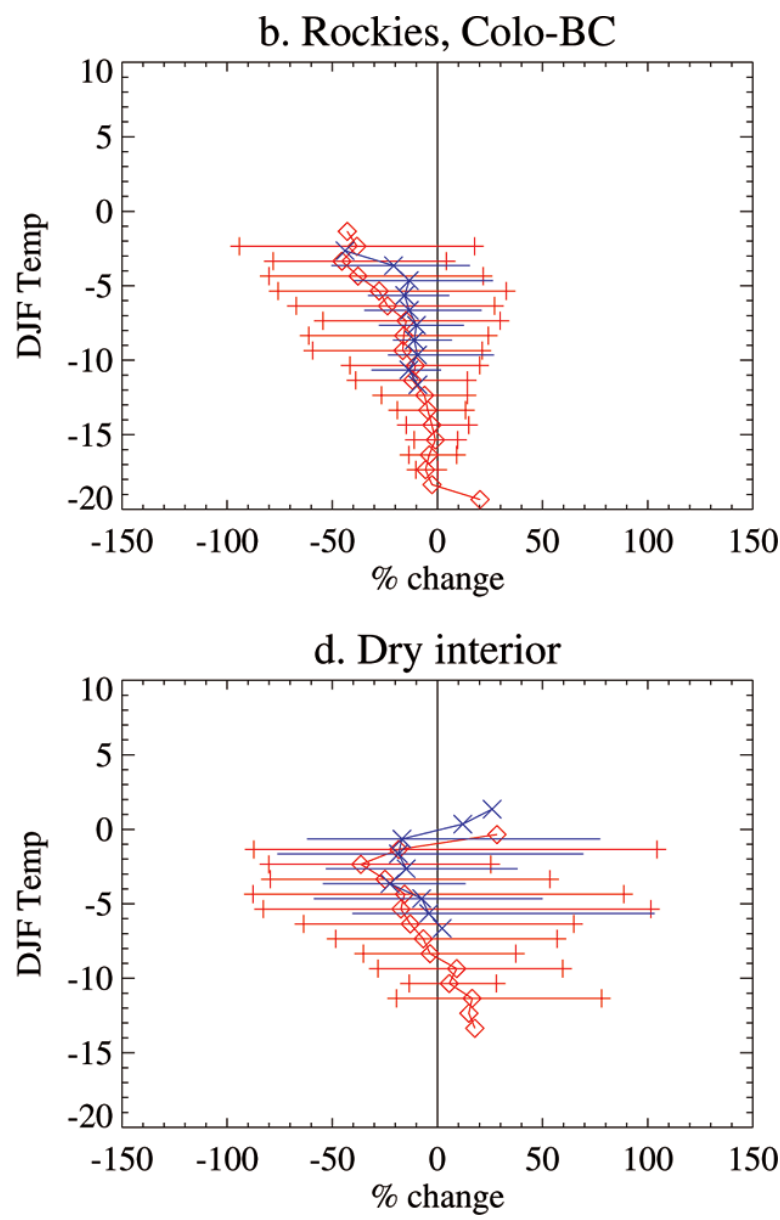

FIG. 2. Mean trends as shown in Fig. I, binned by Dec-Feb temperature for the domains indicated in Fig. I. Observations shown by blue crosses, VIC by red diamonds. For any bin with at least 10 values, the span from the I0th to 90th percentiles is shown. Observed and VIC curves are offset by $0.2 \mathrm{~K}$ for clarity (bins are the same in both). VIC results are shown only for grid points where the mean I Apr SWE exceeds 5 mm. 
a. Cascades

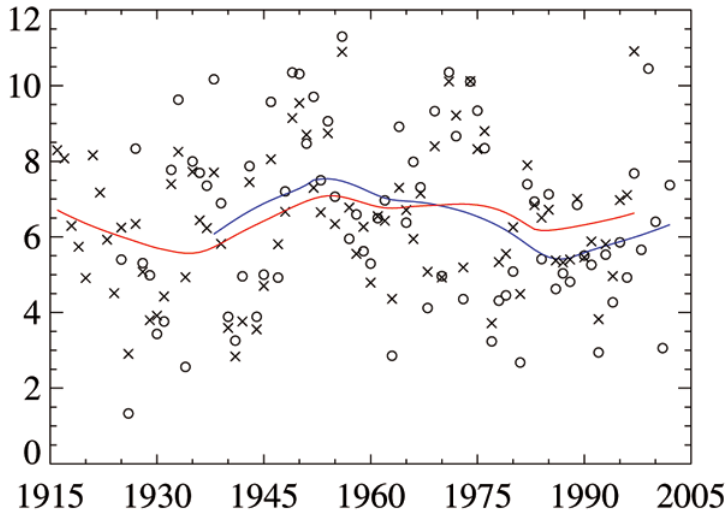

\section{c. California}

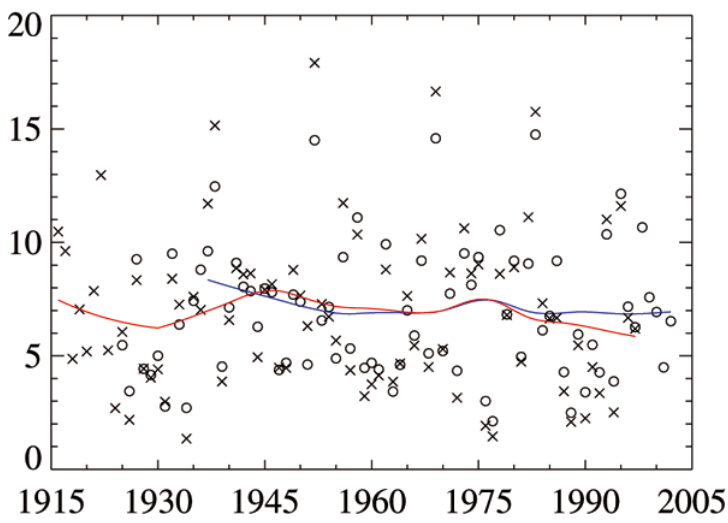

b. Rockies

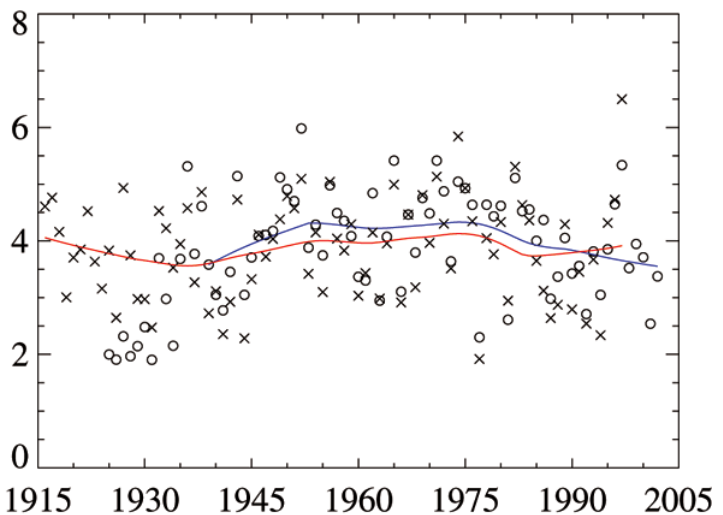

FIG. 3. Time series of regional mean I Apr SWE for the domains indicated, for observations (circles) and VIC (crosses). Smooth curves are added for VIC (red) and for the period of observations when at least half the locations had data (blue). Ordinate is SWE (cm), and the VIC time series for each region is scaled so that the mean is the same as for the observed regional mean.

sites experiencing the largest relative losses, and nonnegative trends occurring only at the coldest locations, which are not sampled by the snow course observations. It is also interesting that snowfall in these two regions is sufficiently heavy that many sites with a mean winter temperature above $0^{\circ} \mathrm{C}$ retain snow until 1 April. In the colder Rockies and interior regions (Figs. 2b,d), the trends still depend on midwinter temperature, but only weakly, and the large precipitation trends are a much more prominent factor in the SWE trends.

Differences between trends estimated from the VIC simulations and from observations (especially evident in California, Fig. 2c) have a number of possible causes. These include a) VIC's meteorological driving data under (or over) estimates temperature and precipitation trends at high elevation; b) snow courses undersample high elevations (and, in California, low elevations); and c) negative trends in the observations could be enhanced by canopy growth at the edges of snow courses. A detailed analysis is beyond the scope of this paper, but at many of the California sites the VIC grid cell elevation is substantially below the snow course location, leading to mean precipitation values that are too low, mean temperature values that are too high, and temperature sensitivity that is too high.

\section{TEMPORAL BEHAVIOR OF REGIONAL}

MEAN SWE. Snow course data are aggregated for each region in Fig. 1 by first converting each reasonably complete (having data at least $65 \%$ of the time between 1925 and 2002) time series of SWE to a time series of $z$ scores by subtracting the mean and normalizing by the standard deviation, then for each year averaging the normalized values and converting back to SWE using the mean and standard deviation averaged over all the time series in the region (as in Clark et al. 2001 and Mote 2003a). These regionally aggregated data are compared (Fig. 3) with simple area 
averages for 1 April SWE, which are rescaled to have the same mean as the observations. The means are different because the regional aggregation is composed of unevenly distributed snow course records with different periods of record, and snow courses tend to be sited in relatively flat, forested locales (valleys and benches) rather than the full range of terrain. Even though the two approaches summarize regional snowpack in somewhat different ways, the interannual and interdecadal variations agree quite well: correlations between observed and modeled regional SWE are 0.88 for the Cascades, 0.75 for the Rockies, 0.96 for California, and 0.77 for the interior. As can be seen in Fig. 3, in all regions SWE probably declined from 1915 to the 1930s, rebounded in the 1940s and 1950s, and, except for a peak in the 1970s, has declined since midcentury.

Changes from the 1930s to the 1990s were generally modest, but in all regions except California there were substantial declines since midcentury (Table 1). In most cases the declines in SWE exceeded the declines in precipitation.

CAUSES: THE CLIMATIC CONTEXT. Of crucial importance in interpreting these variations and trends is an understanding of the separate roles of seasonal temperature and precipitation, and other factors like site changes, in forming 1 April snowpack. Although great care is taken to ensure long-term consistency of the site and observational methods for snow courses, various nonclimatic factors could influence snow course data over the course of decades. These include changes in forest canopy, changes in land use around the site, changes in use of the site, and site moves. Forest canopy strongly influences snow accumulation: although care was taken in siting snow courses in natural clearings, forest encroachment or overstory growth could significantly reduce snow accumulation on the ground over time. The reverse is also true: clearing of the forest, whether for development (e.g., road or parking lot) or timber harvest, or stand-replacing fire could significantly and suddenly increase snow accumulation. Some snow courses have had to be moved, for example, because recreational use of the course (i.e., snowmobiling and skiing) began to significantly affect snow density
(S. Fox 2004, personal communication), which could affect the rate of melt, or because a reservoir expansion inundated the snow course (S. Pattee 2003, personal communication). Finally, the mean date of observation of so-called 1 April snowpack has changed over time: whereas many sites were formerly visited a week or more before 1 April, improvements in travel have shifted the mean date later (R. Julander 2004, personal communication).

Except for the date of observation, which is well documented, insufficient digitized documentation (metadata) exists to evaluate the influence of these nonclimatic factors for each of the 1144 snow courses. However, inspection of Figs. 1 and 2 strongly suggests that it is climatic factors that have played a dominant role in influencing the regional mean trends. Variations and trends in VIC are driven only by climatic factors, and to the extent that they agree with observations site by site or in aggregate, it suggests that the observations reflect only minimal influence from nonclimatic factors. The agreement between VIC and observations in the dependence of trends on mean site temperature (Fig. 2) is particularly compelling. Discrepancies evident in Fig. 3 and Table 1 can partly be explained by the differences in spatial sampling (Fig. 2): the observations undersample high elevations and hence would tend to overestimate temperature-driven declines. Difficulties in simulating snowpack in California (Figs. 2 and 3, Table 1) may relate to interpolation of meteorological observations. Since our main concern here is evaluating the effects of climatic fluctuations and changes, we evaluate the strength of climatic connections to the SWE. Further aspects are explored by HMCL.

To calculate the relative influences of temperature and precipitation on 1 April SWE, we use three different approaches: correlating SWE with winter temperature and precipitation, examining daily SNOTEL 
(r1, r2), Apr1, 1960 to 2002

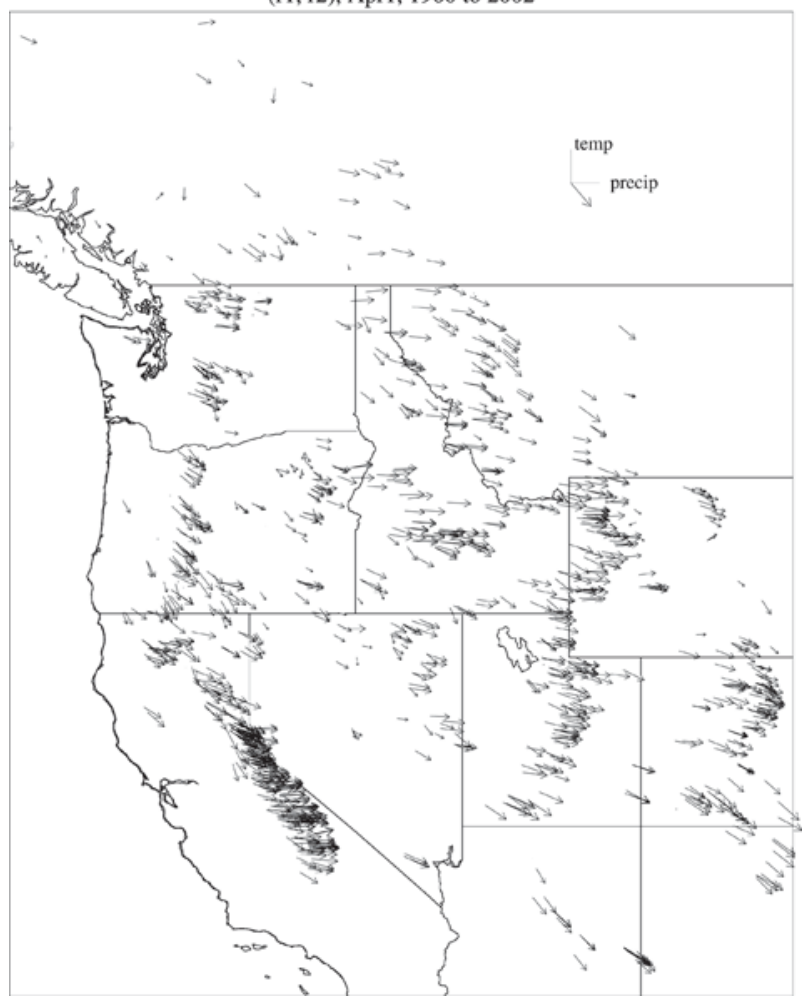

FIg. 4. Correlations between I Apr SWE at snow course locations and Nov-Mar precipitation (x direction) and temperature ( $y$ direction) at nearby climate stations. Virtually every snow course has significantly positive correlations with precipitation, as expected. Most snow courses, especially in the Cascades and in the Southwest, also have significantly negative correlations with temperature, indicating sites where an effect of regional warming should be evident. The reference arrow indicates a correlation of 1.0 in each direction.

data for evidence of midseason melting, and running the VIC model using fixed annual precipitation. First, we calculate at each snow course the correlation during the entire period of record between 1 April SWE and November-March temperature and precipitation taken from nearby climate stations; see the "Data and Model" section for details. These results are plotted in Fig. 4. Throughout the domain, the correlation with precipitation is positive, as expected (i.e., the vectors point eastward). In the warmer parts of the domain-Washington, Oregon, northern California, and the Southwest-there is a substantially negative correlation with temperature (the vectors point southward). In some places the correlation with temperature is stronger than the correlation with precipitation. Almost nowhere is the correlation with temperature positive, and nowhere is it greater than 0.2: warming by itself essentially never leads to greater snow accumulation.

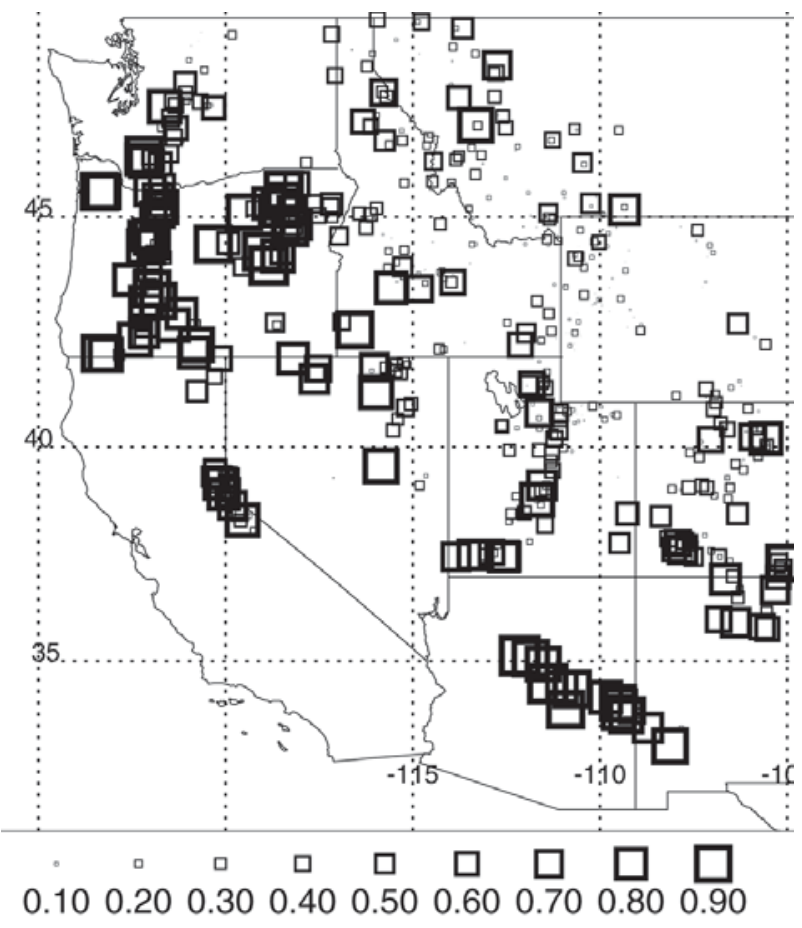

FIG. 5. Correlations from SNOTEL data of total daily melt events (the sum of negative changes in SWE from I Oct to 3 I Mar) and I Apr SWE. The size of the square corresponds to correlation, and all correlations are negative. In the warmer mountains, winter melt events have a strong (negative) influence on I Apr SWE.

The implication of this figure in conjunction with Fig. 2 is that the mountains in the Cascades and northern California have the greatest sensitivity to temperature, and regional warming in the absence of strong increases in precipitation would produce large declines of spring snowpack. Some locations in the interior West and Rocky Mountains are also susceptible to warming, but most are so cold that a warm winter has little effect on spring snowpack (see also Fig. 2), and winter precipitation is the major factor.

Seasonal means of temperature and precipitation tell only part of the story. With daily SNOTEL data, we can examine the role of winter precipitation and melt events in producing 1 April SWE. Figure 5 shows the correlation between total melt events (day-to-day negative changes in SWE) and 1 April SWE: melt events play a large role in determining final snowpack in most sites in Oregon and some sites in southern Washington, Nevada, California, and the Southwest. In the Rockies, melt events are insignificant at most sites before 1 April. These results, in combination with those of Fig. 4, imply that warming produces lower spring SWE largely by increasing the frequency of melt events, not by simply enhancing the likelihood of rain instead of snow. 
a. temperature, 1930 to 1997

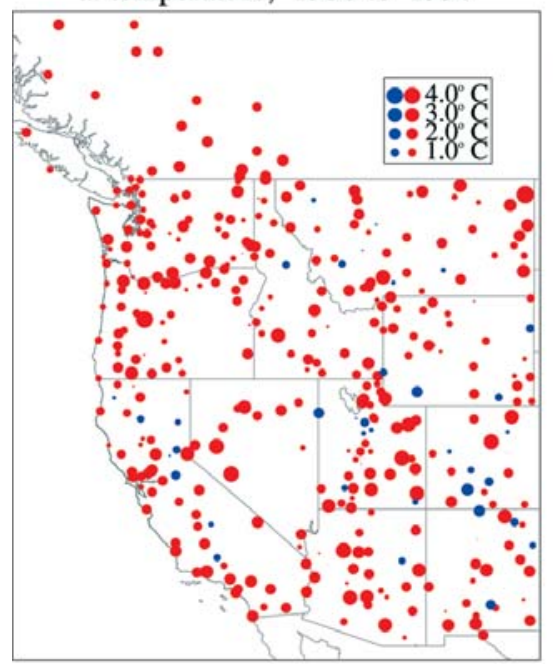

c. precipitation, 1930 to 1997



Fig. 6. Linear trends in Nov-Mar (a), (b) temperature and (c), (d) total precipitation over the period indicated. For temperature, negative trends are indicated by blue circles, and positive trends by red circles; values are given in degrees per century. For precipitation, trends are given as a percentage of the starting value (1930 or 1950), and positive trends are shown as blue circles. b. temperature, 1950 to 1997

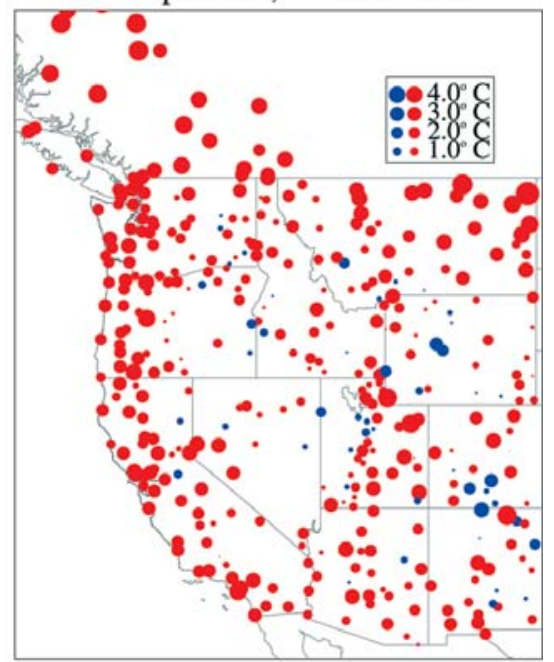

d. precipitation, 1950 to 1997

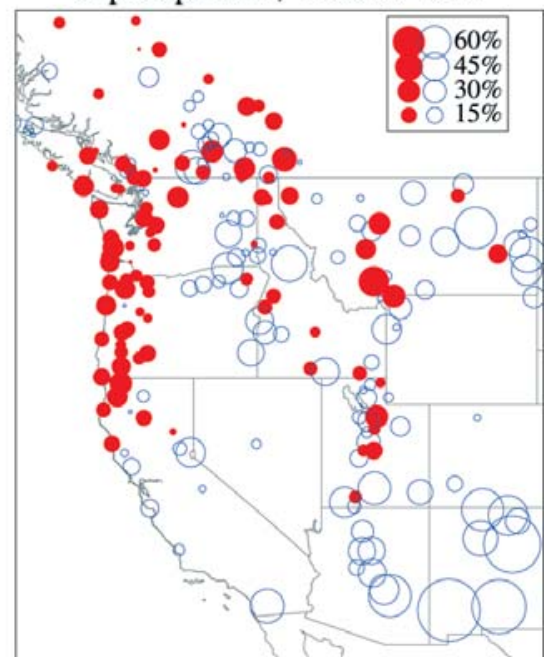

positive during 1950-97 except in the western parts of British Columbia, Washington, and Oregon, and parts of the northern Rockies. Relative changes of $+30 \%-100 \%$ were common in the Southwest; at one location in New Mexico, November-March precipitation tripled from the 1950s to the 1990-97 period. The trends and variability in SWE (Figs. 1-3) can be seen approximately as the result of competition between fairly monotonic warming-driven declines at all but the highest altitudes and more precipitation-driven increases and decreases. In the Southwest and in spots elsewhere in the West, high precipitation in recent decades has produced big increases in snowfall, resulting in higher SWE despite higher temperatures. In the Cascades, very large declines resulted from a double blow of decreases in precipitation and large increases in temperature in a region where snow courses have high temperature sensitivity (Fig. 4).

Are low-elevation climate stations representative of climate fluctuations in nearby mountains? And over what distances? Whereas the stations in the USHCN dataset

The implications of Figs. 1-5 are clearer if we consider climatic trends as well, using USHCN data for the November-March snow accumulation season (Fig. 6). Trends in temperature were overwhelmingly positive both from 1950 to 1997 and from 1930 to 1997: almost $90 \%$ of stations had positive trends in both intervals, though the rate of warming was faster in the 1950-97 time period. For the 1950-97 period, over half of the stations had trends exceeding $1^{\circ} \mathrm{C}$ century $^{-1}$, and about half of the stations had statistically significant trends, with a mean warming of $1.6^{\circ} \mathrm{C}$ century $^{-1}$.

Precipitation trends (Figs. 6c,d) are more variable: overwhelmingly positive during 1930-97 and mostly that have temperature records are fairly uniformly distributed around the West, those with precipitation records are far fewer and less well distributed, especially in Nevada, Wyoming, and the southern half of California, presenting more of a challenge to our efforts to relate trends in SWE to trends in precipitation. Even where there are relatively dense observations of precipitation, like western Oregon, the nearest climate stations for most snow courses are tens of kilometers away in very different terrain (broad valleys and plains) and typically $1 \mathrm{~km}$ or more lower in altitude.

Despite these large differences, the climate observations seem to be able to characterize variability in 
mountain SWE with a high degree of success. We used simple multiple linear regression to characterize 1 April SWE at each snow course as a function of November-March temperature and precipitation from the nearest five climate stations. Using these regression coefficients, a climate-derived SWE value can be calculated for each year (1960-2002) and compared with the observed SWE: the mean of the correlations between these pairs of time series is 0.71 , and only $3 \%$ have correlations below 0.3 ; most of these are in Wyoming, where USHCN precipitation is sparse, or southwestern British Columbia, where SWE may be more sensitive to the details of landfalling storms than to the mean climate conditions during the season. Given the high correlation between winter climate and 1 April SWE, it seems reasonable to surmise that trends in temperature and precipitation at low elevations are roughly representative of trends at higher elevations, though one can also speculate about why the trends might be larger at higher elevation.

Further confirmation of the dominance of temperature trends in many areas comes from examining a VIC hydrologic simulation in which precipitation totals were forced to be the same each month of the year but temperature was allowed to vary as observed. In this "fixed precipitation" run, the broad pattern of trends is rather similar (not shown), but only $3 \%$ of grid points have positive trends and the elevation dependence suggested by Figs. $1 \mathrm{~b}$ and 2 is consistently clear (Fig. 7). These results strongly suggest that essentially the entire mountain West would be experiencing negative trends in SWE were it not for increasing precipitation trends counteracting the effects of observed positive trends in temperature.

In short, many snow courses recorded a decline in 1 April SWE even though precipitation evidently increased. That is, increases in precipitation were generally insufficient to overcome declines caused by strong regional warming. In the Cascades, Pacific decadal oscillation (PDO)-related declines in precipitation from 1950 to 1997 accentuated declines caused by regional warming.

CONCLUSIONS. Widespread declines in springtime SWE have occurred in much of the North American West over the period 1925-2000, especially since midcentury. While nonclimatic factors like growth of forest canopy might be partly responsible, several factors argue for a predominantly climatic role: the consistency of spatial patterns with climatic trends, the elevational dependence of trends, and, most important, the broad agreement with the VIC simulation.
Increases in SWE from about 1930 to 1950 in most regions were caused by increases in precipitation. In areas with moderate winter temperatures, increases in precipitation since 1950 were generally insufficient to overcome warming-driven losses. Cold, highelevation areas and those with very large increases in precipitation (the Southwest) showed positive trends in SWE from 1950 to 1997. The Oregon Cascades experienced the largest losses in the West, owing to a combination of high temperature sensitivity and declines in precipitation from 1950 to 1997.

An important question concerns the causes of the observed interdecadal variability and trends in climate and SWE. Could the declines be a result solely of cyclical climate variability, like the PDO (Mantua et al. 1997)? There is no doubt that year-to-year and decade-to-decade fluctuations in the West's temperature and precipitation (Mantua et al. 1997) and SWE (Clark et al. 2001) are at least partly related to PDO and to El Niño-Southern Oscillation. As for trends, perhaps a third of the November-March warming trend in the Northwest since 1920 can be attributed to Pacific Ocean climate fluctuations (Mote 2003b). And the large increases in precipitation in the Southwest are consistent with the 1977 change in phase of the PDO. However, only a small fraction of the variance of precipitation is explained by any of the Pacific climate indices, and, more importantly, the widespread and fairly monotonic increases in temperature exceed what can be explained by Pacific climate vari-

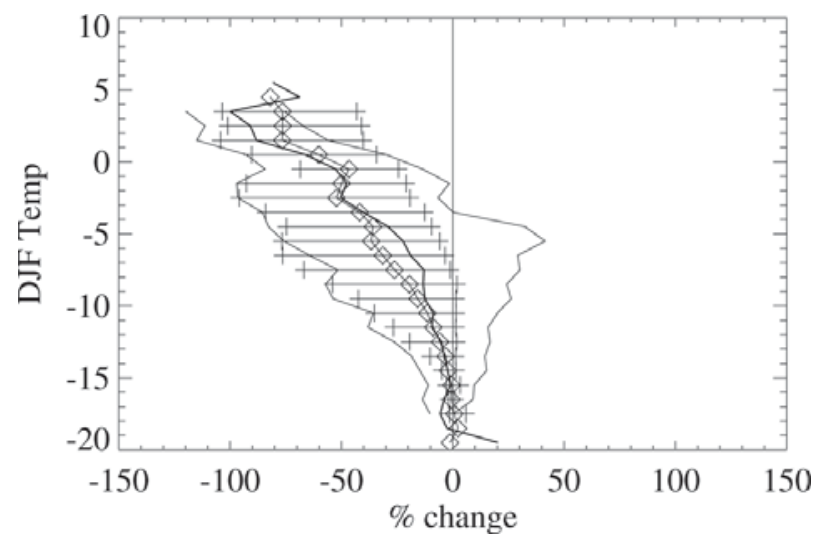

FIG. 7. Trends in I Apr SWE, 1950-97, binned by mean temperature as in Fig. 2 but for the entire West. Connected diamonds indicate the mean, and + symbols indicate 10 th and 90 th percentiles from a VIC simulation in which interannual variations in precipitation were removed at each grid point by constraining annual precipitation to be the same each year. Connected plain curves indicate the same statistics but for the VIC simulation shown in Fig. 2. 
ability and are consistent with the global pattern of anthropogenic temperature increases (Folland et al. 2001). This question of decadal variability is explored further in another paper (HMCL).

We are left, then, with the most important question: Are these trends in SWE an indication of future directions? The increases in temperature over the West are consistent with rising greenhouse gases, and will almost certainly continue (Cubasch et al. 2001). Estimates of future warming rates for the West are in the range of $2^{\circ}-5^{\circ} \mathrm{C}$ over the next century, whereas projected changes in precipitation are inconsistent as to sign and the average changes are near zero (Cubasch et al. 2001). It is therefore likely that the losses in snowpack observed to date will continue and even accelerate (Hamlet and Lettenmaier 1999a; Payne et al. 2004), with faster losses in milder climates like the Cascades and the slowest losses in the high peaks of the northern Rockies and southern Sierra. Indeed, the agreement in many details between observed changes in SWE and simulated future changes is striking and leads us to answer the question at the beginning of this paragraph in the affirmative. It is becoming ever clearer that these projected declines in SWE, which are already well underway, will have profound consequences for water use in a region already contending with the clash between rising demands and increasing allocations of water for endangered fish and wildlife.

ACKNOWLEDGMENTS. We wish to thank the snow survey offices and hundreds of dedicated snow surveyors with the Natural Resources Conservation Service, the California Department of Water Resources, and the BC Ministry of Sustainable Resource Management for providing the snow course data. Thanks also to Lara Whitely Binder for helpful comments on the manuscript. This publication is funded in part by the Joint Institute for the Study of the Atmosphere and Ocean under NOAA Cooperative Agreement NA17RJ1232. The statements, findings, conclusions, and recommendations are those of the authors and do not necessarily reflect the views of the National Oceanic and Atmospheric Administration or the Department of Commerce.

\section{REFERENCES}

Cayan, D. R., S. A. Kammerdiener, M. D. Dettinger, J. M. Caprio, and D. H. Peterson, 2001: Changes in the onset of spring in the western United States. Bull. Amer. Meteor. Soc., 82, 399-415.

Christensen, N. S., A. W. Wood, N. Voisin, D. P. Lettenmaier, and R. N. Palmer, 2004: Effects of cli- mate change on the hydrology and water resources of the Colorado River Basin. Climatic Change, 62, 337-363.

Clark, M. P., M. C. Serreze, and G. J. McCabe, 2001: The historical effect of El Niño and La Niña events on the seasonal evolution of the montane snowpack in the Columbia and Colorado River basins. Water Resour. Res., 37, 741-757.

Cubasch, U., G. A. Meehl, and G. J. Boer, 2001: Projections of future climate change. Climate Change 2001: The Scientific Basis. Contribution of Working Group I to the Third Assessment Report of the Intergovernmental Panel on Climate Change, J. T. Houghton et al., Eds., Cambridge University Press, 525-582.

Daly, C., R. P. Neilson, and D. L. Philips, 1994: A statistical-topographic model for mapping climatological precipitation over mountain terrain. J. Appl. Meteor., 33, 140.

Folland, C. K., and Coauthors, 2001: Observed climate vriability and change. Climate Change 2001: The Scientific Basis. Contribution of Working Group I to the Third Assessment Report of the Intergovernmental Panel on Climate Change, J. T. Houghton, et al., Eds., Cambridge University Press, 99-181.

Groisman, P. Ya., T.R. Karl, and R.W. Knight, 1994: Observed impact of snow cover on the heat balance and the rise of continental spring temperatures. Science, 263, 198-200.

Groisman, P. Ya., R.W. Knight, T.R. Karl, D.R. Easterling, B. Sun, and J.H. Lawrimore, 2004: Contemporary changes of the hydrological cycle over the contiguous United States: trends derived from in situ observations. J. Hydrometeor., 5, 64-84.

Hamlet, A. F., and D. P. Lettenmaier, 1999a: Effects of climate change on hydrology and water resources in the Columbia River basin. J. Amer. Water Resour. Assoc., 35, 1597-1623.

— casting based on ENSO and PDO climate signals. J. Water Resour. Planning Manage., 125, 333-341.

—, D. Huppert, and D. P. Lettenmaier, 2002: Economic value of long-lead streamflow forecasts for Columbia River hydropower. J. Water Resour. Planning Manage., 128, 91-101.

— H. S. Park, D. P. Lettenmaier, and N. Guttman, 2005: Efficient methods for producing temporally and topographically corrected daily climatological data for the continental U.S. J. Hydrometeor., in press.

Karl, T. R., C. N. Williams Jr., F. T. Quinlan, and T. A. Boden, 1990: United States Historical Climatology Network (HCN) serial temperature and precipitation data. Publ. 304, Environmental Science Division, Carbon Dioxide Information and Analysis 
Center, Oak Ridge National Laboratory, Oak Ridge, TN, 389 pp.

Laternser, M., and M. Schneebeli, 2003: Long-term snow climate trends of the Swiss Alps (1931-99). Int. J. Climatol, 23, 733-750.

Liang, X., D. P. Lettenmaier, E. F. Wood, and S. J. Burges, 1994: A simple hydrologically based model of land surface water and energy fluxes for general circulation models. J. Geophys. Res., 99, 14 415-14 428.

Mantua, M. J., S. R. Hare, Y. Zhang, J. M. Wallace, and R. C. Francis, 1997: A Pacific interdecadal climate oscillation with impacts on salmon production. Bull. Amer. Meteor. Soc., 78, 1069-1079.

Mote, P. W., 2003a: Trends in snow water equivalent in the Pacific Northwest and their climatic causes. Geophys. Res. Lett., 30, 1601, doi:10.1029/ 2003 GL017258.

$\longrightarrow, 2003 \mathrm{~b}$ : Trends in temperature and precipitation in the Pacific Northwest during the twentieth century. Northwest Sci., 77, 271-282.

Payne, J. T., A. W. Wood, A. F. Hamlet, R. N. Palmer, and D. P. Lettenmaier, 2004: Mitigating the effects of climate change on the water resources of the Columbia River basin. Climatic Change, 62, 233-256.

Regonda, S.K., B. Rajagopalan, M. Clark, and J. Pitlick, 2005: Seasonal cycle shifts in hydroclimatology over the western United States. J. Climate, 18, 372-384.

Robinson, D. A., 1999: Northern Hemisphere snow cover during the satellite era. Preprints, Fifth Conf. on Polar Meteorology and Oceanography, Dallas, TX, Amer. Meteor. Soc., 255-260.

Scherrer, S. C., C. Appenzeller, and M. Laternser, 2004: Trends in Swiss alpine snow days-The role of local and large-scale climate variability. Geophys. Res. Lett., 31, L13215, doi:10.1029/2004GL020255.

Scott, D., and D. Kaiser, 2004: Variability and trends in United States snowfall over the last half century. Preprints, 15th Symp. on Global Climate Variations and Change, Seattle, WA, Amer. Meteor. Soc., CD-ROM, 5.2 .

Serreze, M. C., M. P. Clark, R. L. Armstrong, D. A. McGinnis, and R. S. Pulwarty, 1999: Characteristics of the western United States snowpack from snowpack telemetry (SNOTEL) data. Water Resour. Res., 35, 2145-2160.

Snover, A. K., A. F. Hamlet, D. P. Lettenmaier, 2003: Climate-change scenarios for water planning studies. Bull. Amer. Meteor. Soc., 84, 1513-1518.

Stewart, I. T., D. R. Cayan, and M. D. Dettinger, 2005: Changes toward earlier streamflow timing across western North America. J. Climate, in press.

Vincent, L. A., and D. W. Gullett, 1999: Canadian historical and homogeneous temperature datasets for climate change analysis. Int. J. Climatol., 19, 1375.

Wood, A. W., E. P. Maurer, A. Kumar, and D. P. Lettenmaier, 2002: Long range experimental hydrologic forecasting for the eastern U.S. J. Geophys. Res., 107, 4429, doi:10.1029/2001JD000659. 